\title{
DA BIOPOLIITICA À NECROPOLÍTICA CONTEMPORÂNEA: IMPLICAÇÕES DO [NEO]LIBERALISMO NA GOVERNAMENTALIDADE E A TAREFA DESCOLONIAL NO BRASIL ${ }^{1}$
}

\author{
FROM BIOPOLITICS TO CONTEMPORARY NECROPOLITICS: IMPLICATIONS OF \\ [NEO]LIBERALISM ON GOVERNMENTALITY AND THE DECOLONIAL TASK IN BRAZIL
}

Leonardo Marques Kussler ${ }^{2}$

\section{RESUMO}

O tema da política sobre a vida é marcado por uma mudança na forma de governo exercida na institucionalização do biopoder, especialmente a partir da entrada do capitalismo como elemento balizador da governamentalidade. No presente artigo, o objetivo principal é mostrar como a biopolítica governamental, notadamente proposta pelos estudos de Michel Foucault, nos anos 70, desdobra-se e lastreia a tese da necropolítica de Achille Mbembe e suas implicações práticas na contemporaneidade. Para isso, comparo alguns excertos de textos de Foucault, Fanon, Mbembe, Deleuze, Agamben, entre outros, no intuito de explorar como a biopolítica está presente na lógica de controle social, implementada e refinada tecnologicamente por governos, o que pode levar a diversos movimentos persecutórios e preconceituosos com determinados grupos sociais. Por fim, aponto como tais necropolíticas podem ser identificadas no Brasil atual, especialmente com base em relatórios de violência aqui analisados, estudos sobre desigualdade étnico-racial-social e combate socialmente seletivo no enfrentamento da pandemia da Covid-19, destacando a relevância e a atualidade de se discutir tais conceitos sob perspectiva descolonial.

Palavras-chave: Biopolítica; Michel Foucault; Necropolítica; Achille Mbembe; Filosofia descolonial.

\begin{abstract}
The theme of politics on life is marked by a change in the form of government exercised in the institutionalization of biopower, especially since the entry of capitalism as a guiding element of governmentality. In the present article, the main objective is to show how governmental biopolitics, notably proposed by the studies of Michel Foucault, in the 1970s, unfolds and supports the thesis of Achille Mbembe's necropolitics and its practical implications in contemporary times. To do so, I compare some excerpts from texts by Foucault, Fanon, Mbembe, Deleuze, Agamben, among others, in order to explore how biopolitics is present in the logic of social control, implemented and technologically refined by governments, which can lead to several persecutory and prejudiced movements towards certain social groups. Finally, I point out how such necropolitics can be identified currently in Brazil, especially based on reports of violence analyzed here, studies on ethnic-racial-social inequality and socially selective combat in facing the Covid-19 pandemic, highlighting the relevance and topicality of discussing such concepts from a decolonial perspective.
\end{abstract}

Keywords: Biopolitics; Michel Foucault; Necropolitics; Achille Mbembe; Decolonial philosophy.

1 Artigo original escrito a partir da provocação do dossiê 'Política e necropolítica na contemporaneidade'.

2 Doutor em Filosofia pela UNISINOS, pesquisador visitante FAPEPI/CNPq na UFPI. E-mail: leonardo.kussler@gmail.com 


\section{INTRODUÇÃO}

Um dos autores mais celebrados nas pesquisas sobre a biopolítica é Michel Foucault. No final dos anos 70, quando o autor propôs o curso sobre a arqueogenealogia da biopolítica, no Collège de France, não a conceitualizou somente a partir do ponto de vista filosófico. Aliás, o que menos se encontra no livro editado a partir das gravações dessas aulas é uma definição que se prende apenas no conceito de biopolítica, mas especialmente as diferentes formas que o biopoder - o poder de um determinado modo de governo sobre a vida de indivíduos em uma determinada comunidade - se desdobra na história. A proposta do autor tenta explorar a passagem dos modos de governar até meados do séc. XVIII e a inclusão decisiva da economia na arte de governar, apontando como o [neo]liberalismo adentra na esfera do controle social, trazendo um novo modo de governar não mais súditos, mas populações. É com base nessa proposta que o conceito de necropolítica é proposto, décadas depois, expondo a relação de governante-governado como uma política da morte, como veremos.

Com base nessa premissa, o presente artigo aborda, na primeira seção, os desdobramentos da biopolítica, da governamentalidade e do controle social a partir da obra foucaultiana. Para tal, parto da noção de que, desde as reflexões da sociedade disciplinar, quando Foucault se debruça a explicar o funcionamento dos mecanismos de poder no tecido social, pode-se relacionar, de certa forma, a implicação do desenvolvimento capitalista na sociedade, em que há uma crescente tentativa do controle dos corpos e da separação dos espaços sociais. O mercado, por sua vez, também funciona como um modo de construção da verdade, impondo um modo de controle estatístico e sutil da vida humana. Tal racionalidade de governo, como mostrarei, opera no nível do gerenciamento da vida, permitindo que determinadas formas de vida sejam priorizadas em detrimento de outras. Explorarei também como tal foco no individualismo produz uma sociedade mais egoísta e alienada da realidade e inclusive de si mesma, uma vez que a própria vida é o produto a ser vendido. Por fim, analisarei como o percurso foucaultiano inspira as discussões sobre formas de governo no pensamento de Agamben, Levitsky e Ziblatt, que dão continuidade à discussão do controle das vidas humanas por meio do Estado e das consequências do aumento da amplitude do controle social que acabam por minar democracias contemporâneas.

A segunda seção parte dos desdobramentos da biopolítica quando adentra ao campo da chamada necropolítica. A partir da tese original e necessária de Mbembe, proponho um retorno às inspirações filosóficas de Fanon, tratando do elemento descolonial na discussão para melhor contextualização do tema na realidade brasileira contemporânea. Proponho, pois, uma leitura da noção de colonizado a partir das dimensões geopolítica e cultural, que expressam as formas de controle mais tradicionais até as mais sutis, presentes nas sociedades contemporâneas. A partir daí, proponho uma análise relacional dos corpos disciplinados com os corpos colonizados, reforçando, a partir das reflexões de Foucault, Fanon e Mbembe, como há um processo de coisificação nas diferentes formas de vida que não interessam ao Estado-mercado.

A argumentação construída aqui busca explorar como a biopolítica traduzida em necropolítica, isto é, a política da morte, explica em boa medida a forma como o Estado brasileiro reconhece (ou não) determinados segmentos étnicos e sociais de sua própria sociedade. Junto a isso, abordo alguns elementos relativos às formas de controle mais sutis e tecnológicas, conforme a proposta de Zuboff, como as 
dos algoritmos, que, carregados de valores e visões de mundo por quem os programa, impessoalizam ainda mais a forma de governar indivíduos, em que, obviamente, algumas vidas são mais protegidas que outras. Por fim, trago alguns estudos comparativos sobre o colonialismo contemporâneo, expresso especialmente pelo racismo estrutural no Brasil, que se revela pelo alto e desigual índice de encarceramento, mortes violentas e descaso no tratamento de doenças da população negra - especialmente no que se refere ao projeto negacionista do governo brasileiro no combate à pandemia de Covid-19 no país.

\section{BIOPOLÍTICA, GOVERNAMENTALIDADE E CONTROLE SOCIAL}

Ao descrever o modus operandi das prisões, Foucault (1987) também explica a sociedade disciplinar, responsável por instituir mecanismos de poder, analisando como a sociedade moderna, juntamente ao desenvolvimento capitalista, dividiu os trabalhadores dóceis/obedientes em lugares, espaços, blocos, a fim de que estes não pudessem formar grupos e bolsões de intercomunicação. Do ponto de vista econômico, não é difícil ver que esta ideia de isolar e localizar corpos humanos, criando distâncias específicas e hiatos entre pessoas, poderia ser relacionada ao locus ocupado na linha de produção, em que cada indivíduo tem um lugar específico para estar, dependendo do papel desempenhado e da posição vertical na hierarquia da empresa.

Deleuze (1990), ao falar sobre a sociedade de controle, destaca que já passamos do tempo do confinamento e nos encaminhamos em direção à formação e ao controle contínuos - a era da especialização -, comunicação instantânea e uma sociedade controlada por computadores que operam para promover os valores do capitalismo. Mas como é possível evitar tal realidade? Deleuze propõe que sejamos delinquentes, que resistamos, muito semelhante à noção foucaultiana de contraconduta. Para o autor, o controle está relacionado à própria ideia de comunicação, de modo que uma forma de confrontar isso seria encontrar estratégias para criar vacúolos de não comunicação, como disjuntores comunicacionais, para burlar a natureza da própria comunicação já corrompida por tais valores mercantilizados.

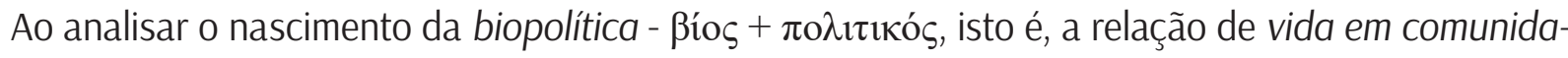
de, mas também de controle social da vida politizada -, Foucault (2008b) aponta para o fato de que o [neo]liberalismo está diretamente implicado ao modo que os governantes conduzem sua arte de governar. Isso se explica pelo fato de o mercado funcionar como uma dimensão para construção da verdade por meio do controle mais sutil da vida humana, especialmente a partir da objetificação matemática desta por meio de estatísticas e dados objetivos que consideram a população como um conjunto de números. O autor trata da noção da racionalidade governamental em uma escala global, pressupondo o capitalismo e seu alcance para tal.

Essa discussão foi possibilitada a partir de seu curso anterior, Segurança, território e população, no qual Foucault (2008a) reflete sobre a própria ideia de biopoder enquanto algo relacionado ao controle sobre a vida de populações, que podem ser simplesmente entendidas como um número, desprovido de qualquer subjetividade e distante da mais simples definição de pessoa humana. Trata-se do momento de ruptura do soberano que detinha o poder de fazer morrer e deixar viver para - com o agenciamento da vida pelo biopoder mercantilizado - o fazer viver e deixar morrer. Como não se fala mais em sujeitos, a gestão da vida passa a considerar termos como taxas de mortalidade, natalidade, fecundidade, infectados, 
doentes, expectativa de vida, entre outros, que permitem também o surgimento de instituições como a medicina moderna, a psiquiatria, o setor prisional e o papel das polícias, por exemplo. Esse modo mais racionalizado de controlar corpos (mentes e almas) das pessoas, chamado de governamentalidade, propõe não apenas o aspecto do comando de alguém - ou um grupo de pessoas - a realizar determinada ação ou a viver de um determinado modo. Mais do que isso, pensar sobre as formas de controle social também nos auxilia a pensar em modos de resistência ou contraconduta, que sempre estão presentes em relações de poder, especialmente nestes presentes na tensão indivíduo-instituição.

Foucault analisa as formas de expressão do biopoder especialmente a partir da lógica do mercado que invade a seara política, principalmente quando as formas de liberalismo - particularmente expressas no utilitarismo britânico, na Alemanha e nos EUA - começam a introjetar valores e modos de governar com base no capitalismo moderno. Tal modo de governar, que se concentra no indivíduo e na suposta liberdade deste, vai se tornando uma forma cada vez mais sedutora aos meios sociais no mundo globalizado, e, a partir dos anos 1930, cria a ilusão de que as pessoas prosperam quando a economia passa a ser gerida com o mínimo de participação do Estado - exceto quando para auxílio das empreitadas malsucedidas. Para Foucault (2008b, p. 301), "O liberalismo, nos Estados Unidos, é toda uma maneira de ser e de pensar. É um tipo de relação entre governantes e governados, muito mais que uma técnica dos governantes em relação aos governados", isto é, um modo de domínio sutil que se fantasia de valor plenamente aceito e pré-condição para a vida contemporânea. Nessa perspectiva em que o foco está no indivíduo - que, em geral, fomenta um comportamento social egoísta e belicoso -, na inação do Estado em participações de ações sociais, Foucault (2008b, 311) afirma que "O homo oeconomicus é um empresário, e um empresário de si mesmo". Isso dialoga com o que defende Han (2012), em sua obra que debate acerca do empreendedorismo de si como última forma de alienação do trabalho, visto que, diferente da análise clássica de Marx, não se trata mais do sujeito que cria um produto que tem valor fora de si, pois a vida é o produto que se vende. No panorama atual, da sociedade do cansaço, o jovem já apresenta estafa mental e física a ponto de não ter condições de trabalhar em poucos anos, traumatizado por achar que a falta de sucesso individual é culpa e demérito exclusivo seu, uma vez que já internaliza acriticamente a ideologia da igualdade social e do self-made man que independe dos meios externos.

Outro importante autor para entendermos o presente tema é Agamben (2004), que, inspirado pelo pensamento de Foucault, propõe suas teses acerca do constante estado de exceção no qual vivemos enquanto sociedade global, permitindo que governantes instituam políticas totalitárias, eliminem adversários políticos e impeçam que uma determinada categoria de cidadãos seja integrada no sistema político. Como a exceção é um tipo de suspensão do Estado de direito, contemporaneamente, não há limites para seu alcance, criando um imaginário de necessidade, um inimigo comum e um apelo pela vigilância digital, que não pede permissão para cumprir sua função em nome de uma pretensa segurança social que prevalece em detrimento da liberdade individual. Adorno (1998), por sua vez, ao abordar o ocaso do humanismo por conta do desenvolvimento desenfreado e descaracterizado da racionalidade técnica, trata da barbárie de se escrever um poema após Auschwitz, visto que um ato de criação acrítico e enquanto mero produto cultural massificado pelo capitalismo não expressa formas de ser no mundo que destoam de um discurso totalitário. Aqui, há o maior evento histórico de um Estado que exerce o direito de matar, que, em uma lógica totalmente torpe, se justificaria por uma suposta proteção para que outros possam viver. 
A obra de Levitsky e Ziblatt (2018), escrita antes do levante do Capitólio norte-americano decorrente da derrota de Donald Trump nas últimas eleições de 2020, nos permite pensar acerca de alguns aspectos relevantes acerca das técnicas de governamentalidade presentes em diversos episódios históricos. Um deles é a figura do demagogo ou do cínico político, a imagem totalmente ficcional do outsider político, que se promove a partir de uma narrativa falsa que se baseia no esvaziamento político e acaba por minar elementos básicos de qualquer democracia. Essa reflexão conversa com o que Eco (2018) propunha em sua lista de características não sistemáticas e por vezes contraditórias do fascismo eterno, que elenca aspectos como culto à tradição, negação do saber constituído, ação irracional, negação da cultura e da crítica, xenofobia e obsessão conspiratória, prontidão para a luta patriótica, desprezo pelos pobres e fracos, extinção de parlamentos etc. A ideia de uma política do nós vs. eles é parte da pedra basal que impulsiona tais movimentos autoritários, intolerantes e antidemocráticos.

É preciso, pois, buscar formas de mudar alguns aspectos do rumo social, talvez com algo da ideia nietzschiana da estética da existência adotada por Foucault (1985) para defender a ideia de alguém que deseja realizar sua própria transformação de si, na busca por estabelecer uma forma de vida digna de ser mostrada e que, por tanto, pode ser exibida à luz do dia, diferente da [forma de] vida nua, que pode ser descartável, desprotegida, indesejável e não aceita, incapaz de mudar-se por conta (AGAMBEN, 2002). Mais do que isso, há uma forte necessidade de se pensar em modos de vida que confrontem - por meio de manifestações ou talvez performances políticas - os controles sutis da contemporaneidade, conscientizando mais pessoas do papel da defesa das instituições democráticas e da garantia de um mínimo de direitos, evitando, assim, que populações se tornem alvos.

Na próxima seção, retrataremos alguns elementos acerca dos desdobramentos do biopoder compreendido não apenas como uma forma de relação de poder entre governante-governado, mas enquanto a política da morte. Para tal, abordaremos alguns argumentos de Mbembe, influenciado por Fanon e Foucault, localizando a discussão na realidade contemporânea brasileira e contextualizando isso com alguns dados socioeconômicos do Brasil, especialmente nos últimos anos, devido aos recentes impactos políticos e suas implicações sociais e econômicas, agravadas pela calamidade da pandemia.

\section{DESDOBRAMENTOS DA BIOPOLÍTICA: NECROPOLÍTICA E SUAS IMPLICAÇÕES NO BRASIL CONTEMPORÂNEO}

Um dos recortes mais interessantes feitos a partir do conceito de biopolítica foucaultiano talvez seja o realizado por Achille Mbembe, que o atualiza para um contexto social descolonial ou anticolonial, que nos remete aos estudos também impactantes e inspiradores de Frantz Fanon em décadas passadas. Nesta seção, gostaria de me ater a alguns desdobramentos da necropolítica em um franco diálogo com os autores mencionados acima com o fito de tentar explorar alguns elementos disso na cultura, no constructo social e na realidade do Brasil atual. A pergunta central para nossa reflexão, aqui, pode ser resumida em: em que medida faz sentido falar da necropolítica no Brasil?

Para começo de conversa, podemos partir da tentativa de compreender o que seja colonizado no contexto que tratamos aqui. Para expandir a discussão, sugiro pensar-se acerca de ao menos duas dimensões que talvez possam ajudar a refletir sobre o tema. Uma delas é a dimensão geopolítica, que 
talvez seja a mais conhecida de nós, especialmente por estudarmos já no ensino primário aspectos históricos, econômicos e sociais que explicam, em geral pelo viés do conquistador, como uma nação chega a ser dominada e reduzida à posição de subserviência por meio de eventos belicosos. A segunda dimensão é a cultural, que é muito mais sutil que a primeira, pois não implica diretamente o uso de força, do poder violento irrestrito de tropas que atacam e dizimam uma população em nome de um acordo comercial forçado. O colonialismo cultural é aquele que implementa uma determinada visão de mundo dominante como o padrão de vida a ser almejado, mesmo que, para isso, a cultura e os valores locais tenham que ser descartados em prol de uma homogeneização bárbara.

Para Mbembe (2001), pensar a partir da lógica pós-colonial passa por uma reabilitação das noções histórico-temporais de era e duração, que, respectivamente, englobam a) uma série de eventos e relações, que, por sua vez, incluem b) descontinuidades, movimentos, inércias e um enredamento. Junto a isso, retomando alguns aspectos que podemos enxergar em Foucault e Agamben, por exemplo, o autor trata do imaginário de soberania necessário para impor a ordem e a obediência social, seja com base na violência ou no enfraquecimento do direito. Nessa lógica, o direito e as ações tidas como corretas são uniformizadas sob o manto da própria soberania, de modo que o Estado colonial, por assim dizer - especialmente na análise geopolítica e histórica que Mbembe faz de países africanos -, justifica seu modus operandi simplesmente por sua condição imposta de ordem. Assim como Foucault (1987) trata dos corpos disciplinados, Mbembe (2001) fala dos corpos colonizados, que são objetificados ao ponto de não serem mais corpos dignos de respeito, mas coisificados ou bestializados, pois, nessa lógica, as colônias seriam habitadas por selvagens e não são organizadas como um Estado reconhecido, de modo que o constructo social é de uma constante zona de guerra em que o soberano pode matar sem medo de represálias, pois não há reconhecimento do Estado de direito convencional.

Além da perspectiva filosófica, um dos aspectos sociais que une Mbembe a Fanon é a condição de nascer e viver em um país colonizado pela França. Para Fanon (1968), o foco da conscientização social, em termos de identidade e de reconhecimento do potencial formativo inerente aos povos colonizados - mental e fisicamente -, seria não apenas virar as costas à Europa, mas largar a Europa, visto que seus intelectuais nunca deixaram de falar sobre o ser humano, em belos discursos antropológicos, mas sempre massacrando-o ao encontrá-lo, dentro e fora de seus países. Quem é o ser humano considerado pelo humanismo eurocêntrico? Há inclusão do ser humano periférico, colonizado e historicamente desprezado? Fanon (1968) acreditava que seu momento histórico, ainda nos anos 60, era propício para que a sociedade passasse a uma outra forma de se estabelecer, tratando do ser humano de forma emancipadora, marchando dia e noite com todos os seres humanos. O objetivo seria buscar uma postura ética que alia articulação política e movimento social, uma caravana universal de militantes que buscam compreender e mudar o mundo. Ao retratar a cidade do colonizado como um lugar de má fama, em que seres humanos vis nascem e morrem sem que isso importe, Fanon (1968), de certo modo, descreve a lógica do colonizado, a existência do dominado que carece do mais básico sustento, pois é uma cidade com fome, sem o mínimo respeito por seus valores, pois também é uma cidade ajoelhada. Para Fanon (2008), não faz sentido esperar da população menos favorecida que se esforce por adquirir valores abstratos e elevar sua Weltanschauung (visão de mundo) enquanto mal consegue parar em pé por falta de substratos materiais (alimentos). 
Percebe-se, aqui, uma relação no modo como Mbembe trata da perspectiva anticolonial a partir de uma base que Fanon já havia lançado anteriormente. Ainda sobre a lógica da dominação presente nesse panorama sociopolítico, Fanon (2008) trata do poder que é expresso e impresso na linguagem, uma vez que falar é existir de forma absoluta ao outro, pois trata-se de um modo de assumir uma determinada cultura e suportar o peso de uma civilização. O próprio modo de se referir ao colonizado faz parte de um processo de dominação que também é material, pois cristaliza determinados valores que levam décadas ou séculos para serem repensados e, com sorte, alterados. No que tange à temática do racismo, por exemplo, Fanon (2008) afirma que o racista que cria o inferiorizado, e isso nos faz pensar sobre a lógica do domínio expressa por meio da linguagem do dominador, pois a narrativa do vencedor tende a ser fixada como versão oficial nos autos históricos. Ao usar a metáfora das máscaras, Fanon (2008) lança a nós o questionamento sobre o tipo de máscara usado pelo colonizado para conquistar minimamente a tolerância do colonizador e, para isso, aponta como há uma tendência desalentadora de assimilação e sincretismo cultural forçado de valores originários sobrepostos por valores culturais de uma cidade em detrimento de aspectos selvagens não permitidos pelo colonizador.

Quanto à antropologia filosófica tradicional, Mbembe (2017) pontua que o Ocidente, a região mais civilizada do mundo inventou os direitos humanos. Contudo, essa é a mesma racionalidade civilizada que, ao menos desde o iluminismo kantiano, propõe uma racionalidade a partir do horizonte europeu central, destacando que quem está fora daquele eixo cultural e político não é exatamente apto à racionalidade, ainda não alcançou a luz. A partir disso, podemos nos questionar: quem é que pode ser racional? Quem pode ter direitos? Quem a soberania racional decide ser ou não descartável? Ao propor a crítica da razão negra, Mbembe refere-se especialmente às obras de Kant - que, inclusive, têm passagens racistas e etnocêntricas no mínimo problemáticas ${ }^{3}$. Seu argumento tenta reconduzir a discussão de Fanon e Foucault, expondo que o papel da colônia seria o funcionamento enquanto local de exaltação do poder e de renovação da energia nacional da matriz colonial.

Para Mbembe (2017), a expressão de poder, em suas variadas formas, mostra-se ativa especialmente quando se percebe que tanto na literatura, na filosofia, nas artes ou na política, o discurso negro foi dominado pelos eventos de escravidão, colonização e apartheid. O colonizado é separado de si mesmo, desapropriado de si mesmo e, por fim, degradado em sua existência. Por isso que há uma necessidade de se buscar políticas e ações do reconhecimento das origens identitárias culturais e sociais de um determinado povo, pois a identidade leva ao reconhecimento da própria existência e valida aquilo que se é. Para fins de reflexão, podemos pensar que, enquanto pesquisa sobre a biopolítica, Foucault destaca que o liberalismo tem, em seu âmago, uma relação produtiva e destrutiva com a liberdade, mas, para Mbembe (2017), faltou ao autor especificar que o principal ponto histórico da destruição da liberdade foi a escravização dos negros.

3 Conforme mostra o estudo de Gonçalves (2015), há diversos trechos em que Kant trata de uma suposta supremacia racial, assim como discursos claramente racistas e etnocêntricos, que inferiorizam determinadas etnias. Tais trechos podem ser encontrados em Metafísica dos costumes, Fundamentação da metafísica dos costumes, À paz perpétua, Das diferentes raças humanas, entre outros. 
Feito o retrospecto conceitual que mostra a caminhada acadêmica de Mbembe, passamos ao desdobramento da biopolítica ao conceito de necropolítica. ${ }^{4}$ A discussão do autor acerca desta forma de tanathopolítica, de política da morte, parte da premissa foucaultiana do biopoder como forma de exercício de poder e dominação por parte dos governos ao longo da história. A partir da constatação de que a sociedade contemporânea se caracteriza pela separação, pela criação de inimigos - especialmente pelo perfil [neo]liberal e capitalista presente não apenas na organização econômica dos países, mas, como vimos na análise de Foucault, também na governamentalidade destes -, parece haver um desejo de ter um inimigo. Essa identidade presente em diversos países contemporâneos une discursos xenofóbicos, homofóbicos, racistas, etnocentristas e negacionistas em torno de um não eu, um outro que não eu, um diferente ou anormal, que, por essa condição, não merece viver nos ditames do que se considera normal e aceito.

Junto a isso, podemos afirmar que outra característica dos Estados contemporâneos é a noção de que há uma constante sensação de insegurança; basta pensar, por exemplo, na intensificação das narrativas norte-americanas quanto à ascensão de práticas terroristas para justificar suas atrocidades em países do Oriente Médio, sobretudo após o evento nas Torres Gêmeas ainda em 2001. Junto à política do constante estado de guerra há também o estado de vigilância, que, em termos de tecnologias da comunicação, podem ser entendidos como formas mais sutis de controlar as pessoas, especialmente se concordamos com a tese proposta por Zuboff (2019), que propõe que vivemos em uma era do capitalismo da vigilância; que, por meio do grande outro - grandes aparatos tecnológicos de empresas que coletam informações e modificam o comportamento humano -, usa algoritmos e redes sociais alimentados pelo conteúdo que nós mesmos geramos ao existir em meio a essas plataformas.

Na análise de Mbembe (2019), o pensamento e a prática das políticas sempre estão lastreados pelo racismo. Na economia (normatização econômica) do biopoder, o racismo regula a distribuição da morte e das ações violentas do Estado, de modo que a violência e a necessidade criada de uma guerra constante contra inimigos prediletos não sustenta apenas a estabilidade da soberania, do direito desta de mandar/ ordenar, mas também o direito de matar, o exercício do biopoder. Mbembe (2019) usa o exemplo de lógica colonizada contemporânea na região da Palestina, que sofre com o necropoder - poder soberano sobre quem importa ou não matar ou a quem é permitido deixar morrer - que sabota sistematicamente a infraestrutura urbana e rural, em uma atualização das táticas medievais de sitiar uma cidade - acabar com estradas, água, plantações, comunicação etc. Nessa lógica do capitalismo neoliberal presente no âmbito militar surgem, também, as máquinas de guerra, que, para Mbembe (2019), caracterizam-se pelos mercenários armados que terceirizam guerras; uma empresa da morte que permite o descolamento do Estado, que não necessariamente é diretamente identificado, pois não há bandeiras e uniformes caracterizando tais tropas.

De onde vem esse desejo de fazer justiça por meio do sofrimento do outro? Nietzsche (2009) já analisava a suposta satisfação de desejo pelo sofrimento em forma de justiça, como se a pena de alguém justificasse o sofrimento de seu corpo, o martírio, o castigo. Que sentimento estranho é esse que o bicho humano sente em seu interior e, de forma animalesca, expressa por meio da satisfação de recalcar ou

4 Originalmente, a edição inglesa de Necropolitics advém da obra Politiques de l'inimitié, que poderíamos traduzir por políticas da inimizade (tal como na edição de Portugal), com mais de 200 páginas. No Brasil, a obra Necropolítica é uma edição baseada em um ensaio de 2003, com menos de 80 páginas. Para a presente discussão, faço uso da edição inglesa, justamente por ser mais completa e com mais elaborações acerca do tema. 
sublimar seus traumas por meio do sofrimento alheio, na vingança travestida de justiça? Em termos de injustiça proveniente de um passado de colonização geopolítica e cultural, podemos pensar no nosso próprio país, que carrega várias mazelas que dificultam a realização de uma mudança nacional. O Brasil, também na condição de colonizado por um país europeu, Portugal, revela inúmeros aspectos de organização social e domínio entre classes que se assentam até hoje. ${ }^{5}$ Como expurgar, pois, o tipo de relação proveniente da lógica da plantation - isto é, a relação de mercadoria, propriedade e objetificação do senhor para com o escravo nas colônias - de que Mbembe (2019) fala? A análise de Souza (2019) mostra como o racismo e os aspectos coloniais, no Brasil, foram, paulatinamente, substituídos pelo culturalismo, que passou a explicar as diferenças sociais por conta de um estoque cultural herdado, que, curiosamente, tem como seu parâmetro a visão romantizada do cidadão brasileiro com síndrome de vira-lata, que vê no American way of life o ápice do desenvolvimento - eis o colonialismo cultural ao qual me referia anteriormente.

No Brasil contemporâneo, há diversas formas de expressão da biopolítica e da sua derivação, a necropolítica. Nos últimos anos, percebe-se que há uma postura governamental que busca alvos sociais, especialmente pelo aumento da desigualdade, como mostra estudo de Neri (2019); pelo retorno do Brasil ao mapa da fome da ONU, como mostra matéria de Antunes (2020); e pelo sistema carcerário superlotado e nivelado pela cor da pele (ANDRADE, 2020). O Atlas da Violência também demonstra, com dados tristemente reais, que, no Brasil, para cada 1 não negro (branco, amarelo e indígena, de acordo com a nomenclatura do IBGE) vítima de homicídio, há 3 negros (negros e pardos) mortos (CERQUEIRA; BUENO, 2020).

Desde o início da disseminação mundial da pandemia de Covid-19, no início de 2020, o Brasil tem mostrado uma resposta vergonhosa e uma gestão coordenada por uma governamentalidade que fez uso do biopoder de forma extremamente cruel para com as classes menos afortunadas. Enquanto há perdão de dívidas, incentivos e facilitações para as camadas mais abastadas da população, com um vertiginoso aumento de quase $40 \%$ da fortuna de famílias bilionárias brasileiras - fenômeno que ocorreu no mundo inteiro -, como mostra a matéria de Carrança (2020), houve também recorde de desemprego no país, que, conforme análise do IBGE (2021), chegou ao triste patamar de 14,6\%. Porém, o perfil do descaso governamental propositado no Brasil não é apenas social, mas também étnico, visto que, de acordo com levantamento de Bianca Santana (2020), a letalidade da Covid-19 é ao menos cinco vezes maior para negros do que para brancos. Aliás, já está bem consolidada a tese de que a péssima gestão da pandemia foi, de fato, uma governamentalidade necropolítica com alvos específicos pertencentes a um determinado estrato social e, junto a isso, a um recorte étnico-racial do país.

De acordo com o texto de Eliane Brum (2021) e a pesquisa de Ventura, Aith e Reis (2021), não houve apenas omissão do governo federal quando da recusa de dezenas de milhões de vacinas em meados de 2020, assim como na constante minimização da pandemia, falta de discurso em prol do distanciamento social,

\footnotetext{
5 Alguns mitos das análises sociológicas brasileiras da primeira metade do séc. XX criaram uma imagem falaciosa e problemática da identidade do país. Como não relembrar, aqui, do mito da democracia racial de Gilberto Freyre, assim como sua concepção de que a escravização brasileira foi menos segregadora do que a dos EUA e sua passada de pano para a violência dos senhores para com escravos. Há também a leitura possível do homem cordial de Sergio Buarque de Holanda que planifica brasileiros como naturalmente bons, amistosos, avessos à guerra, pouco racionais (pois levados pela emoção). Poderíamos pensar na ideia do cunhadismo, analisado por Darcy Ribeiro para explicar aspectos da miscigenação étnica no Brasil, como se esta fosse uma prática pacífica, pensada para assentar as classes sociais.
} 
promoção de aglomerações Brasil afora e do uso de medicamentos sem eficácia para combater a Covid-19 que, pelo contrário, causam mortes se usados indiscriminadamente -, desprezo pelo uso da máscara, defesa da imunidade de rebanho sem vacina e boicote ao auxílio emergencial. Houve, sim, uma estratégia institucional de ações friamente deliberadas e empregadas enquanto política de Estado - que ainda podem ser julgadas e enquadradas como crimes como o de atentar contra o direito à saúde e outros relativos à segurança interna do país, a depender dos resultados da atual CPI da Covid do Senado Federal -, sabotando as medidas adotadas pelos estados e municípios que tentam conter os efeitos dessa catástrofe sanitária.

De acordo com a pesquisa de Fátima Lima (2018), há alguns paralelos interessantes entre a biopolítica e a necropolítica à brasileira. Com um panorama histórico e cultural permeado pelo sentimento colonial do atraso, é fácil perceber que há uma política em prol da morte de um determinado grupo social que se intensificou muito nos últimos anos, especialmente quando se considera a taxa de homicídios em seu recorte étnico-racial, como explicitado acima, deixando às escâncaras que não se trata apenas de omissão com parte da sociedade, mas uma necropolítica, uma tanathopolítica, uma política de morte deliberadamente implementada. Mas, como afirma Butler (2009), o que essa postura necropolítica deixa claro é que há vidas que não são dignas de luto, pois, na concepção neoliberal e utilitarista - indiretamente higienista -, as vidas não são todas iguais, pois há algumas mais importantes que outras, que podem ser deixadas para morrer.

Para finalizar, atentemos ao fato de que muito disso se vincula com o autoritarismo presente no contexto político brasileiro, especialmente a partir de 2019. No Brasil contemporâneo, podemos enxergar muitos aspectos do levante autoritário desde o golpe de 2016, didaticamente explicado por Castells (2019), que, ao visitar o país para dar palestras, usou o conceito de ditadura sutil para denominar a fase na qual estávamos adentrando, que se explicita por meio de um controle promovido pelo uso irrestrito das redes sociais e pelo desmantelamento da educação. Nesse sentido, a pandemia de coronavírus apenas tornou mais explícita a desigualdade social para uma parcela maior da população brasileira, que, após mais de 400 mil vidas ceifadas pela Covid-196 , ainda sofre na mão de um pequeno grupo social que insiste em ser contra lockdown rigoroso com auxílio financeiro, desdenha da eficácia da vacina e aposta no fomento do desespero da população, obrigando-a a trabalhar sob condições extremamente perigosas, sem segurança e protocolo algum realmente sendo levado a sério. Aparentemente, o que nos resta é buscar formas de compreender melhor as formas de expressão da necropolítica à brasileira para, assim, podermos formar grupos sociais mais articulados e capazes de manifestação e atitudes contrárias para mitigar conceitual e politicamente as pré-condições do atual Estado colonial e voltar a garantir direitos expressamente descritos na constituição brasileira e reiteradamente negados pela falta de zelo e negligência dos deveres do governo federal na defesa da saúde e da vida digna.

\section{CONSIDERAÇÕES FINAIS}

Abordar a temática do poder em sua relação íntima com a vida faz que possamos ler de forma mais adequada as implicações das formas de governo com os seres sociais, e saber como essas 6 Em meados de fevereiro, enquanto o texto era escrito, o número passava de 200 mil. Infelizmente, mas, previsivelmente, o número segue subindo, muito por conta da estratégia do atual governo federal brasileiro. 
governamentalidades foram se modificando ao longo da história pode nos ajudar a compreender nossa atual situação a nível global e local. No presente texto, tentei mostrar como o tema do poder sobre o povo dialoga com as discussões acerca da disciplina social, da mudança de paradigmas de governo, da participação do capitalismo no processo de políticas de gestão social, assim como do processo de descolonização social/cultural e das formas de controle sociais, cada vez mais sutis e prejudiciais ao tecido democrático como um todo.

Desse modo, na primeira seção, propus um mergulho sociofilosófico e interpretativo a partir da obra foucaultiana sobre o tema da biopolítica, elencando como esta se desdobra na temática do controle social, das formas de manifestação de poder e do gerenciamento da vida, que, impulsionado pelo capitalismo de mercado [neo]liberal, propicia novas formas de controle e governo sociais. Como vimos, tais formas de governo associam um duplo distanciamento, seja entre indivíduos de uma determinada comunidade ou entre governantes-governados, reduzindo as subjetividades em individualidades a serem dominadas e conformadas a partir de estatísticas e medições de produtividade mais aparentes e segregadoras. Ainda nessa seção, outro elemento a ser destacado foi a argumentação que parte da reflexão de Foucault e converge com as propostas de Agamben, Levitsky e Ziblatt, especialmente no que concerne ao que se entende como formas de vida a serem governadas, cuidadas ou rechaçadas pelo Estado contemporâneo e no que tange às discussões acerca do enfraquecimento dos mecanismos democráticos nas nações devido ao uso indiscriminado de formas de controle sutis.

Na segunda seção, busquei mostrar alguns trajetos da biopolítica foucaultiana naquilo que Mbembe conceituou por necropolítica. Com fortes inspirações sociofilosóficas de Frantz Fanon, especialmente no que se refere à postura político-filosófica de buscar um modo de ser descolonial em meio a uma realidade que se impõe em uma força amplamente colonizadora, seja do ponto de vista geopolítico quanto cultural. Nessa passagem, argumento que corpos disciplinados podem ser compreendidos como corpos colonizados, combinando as propostas de Foucault, Fanon e Mbembe que apontam para formas de governo que segmentam o tecido social e rotulam determinadas formas de vida como capazes de viver ou que devem ser deixadas para morrer ou, inclusive, ostensivamente mortas. Como forma de contextualização da política da morte no Brasil, defendo que é evidente a predileção social por parte do Estado brasileiro, seja com quem tem direito a viver ou dever de morrer, relacionando isso com as formas de controle mais tradicionais e segregadoras - do ponto de vista socioeconômico e étnico-racial, que se mostra nos alvos sociais a serem invisibilizados, separados e/ou mortos por políticas de Estado - e outras mais tecnológicas e sutis, mas que também carregam pré-conceitos que corroboram tal organização social hostil. Por fim, elenco alguns dados do mapa da violência no Brasil, além de dados da categorização social no sistema carcerário brasileiro e na gestão desastrosa e anticientífica promovida pelo governo federal brasileiro no combate à pandemia de Covid-19, que escancara algumas predileções preconceituosas e higienistas no atual contexto brasileiro.

Ao final, a grande questão deixada a quem lê o presente texto é: como evitar, mesmo que de forma não totalizante, tal situação social? O primeiro passo para que tal necropolítica brasileira seja enfrentada, com suas práticas antidemocráticas e persecutórias a nível social, econômico e político, talvez seja escrever textos como este e fazer ver, dentro e fora do ambiente acadêmico, os resultados catastróficos que deixam. O segundo passo, por sua vez, pode partir de iniciativas da sociedade civil 
organizada, que, a par da situação, consegue engajar um grupo maior e melhor orientado sobre ações que podem ser feitas para conscientizar da tarefa teórico-prática descolonial e mitigar algumas dessas ações, mesmo que em pequena escala. Microrrevoluções e contracondutas em microrregiões podem ter grandes efeitos e formar um grupo social mais coeso, capaz de realizar manifestações importantes e de propor pautas no jogo político. Mesmo dentro de um panorama do capitalismo neoliberal, em que a vida só tem valor do ponto de vista utilitário e o foco recai sempre no indivíduo - nos méritos dos bem-sucedidos e na glamorização da miséria -, propor ações anticoloniais do presente pode impulsionar para uma sociedade futura mais justa e mais autônoma do ponto de vista social, cultural e econômico. Dentro das realidades tão distintas, mais do que nunca, buscar um mundo mais justo e igualitário é um dever de quem, parafraseando Platão e Marx, consegue sair da Caverna e não apenas interpretar, mas mudar o mundo, rompendo elos biopolíticos de exclusão social e lançando perspectivas mais emancipadoras e animadoras para o futuro.

\section{REFERÊNCIAS}

ADORNO, Theodor W. Prismas: crítica cultural e sociedade. São Paulo: Ática, 1998.

AGAMBEN, Giorgio. Homo sacer: o poder soberano e a vida nua I. Belo Horizonte: Editora UFMG, 2002. Estado de exceção. São Paulo: Boitempo, 2004.

ANDRADE, Paula. O encarceramento tem cor, diz especialista. Agência CNJ de notícias, Brasília, 2020. Disponível em: https://cutt.ly/bxb0Vpm. Acesso em: 10 maio 2021.

ANTUNES, André. A volta da fome. Centro de estudos estratégicos da Fiocruz, Rio de Janeiro, 2020. Disponível em: https://cutt.ly/ixb04uo. Acesso em: 10 maio 2021.

BUTLER, Judith. Frames of war: when is life grievable? London; New York: Verso, 2009.

BRUM, Eliane. Pesquisa revela que Bolsonaro executou uma "estratégia institucional de propagação do coronavírus". El País, SP, 2021. Disponível em: https://cutt.ly/dcyNnmU. Acesso em: 10 maio 2021.

CARRANÇA, Thais. Fortuna dos bilionários brasileiros cresceu 39\% em meio à pandemia, diz UBS. Folha de S.Paulo, SP, 2020. Disponível em: https://cutt.ly/Dxb0ibL. Acesso em: 10 maio 2021.

CASTELLS, Manuel. Brasil está entrando em uma "ditadura sutil" com Bolsonaro, diz Castells. Uol Notícias, SP, 2019. Disponível em: https://cutt.ly/SlzLsdf. Acesso em: 10 maio 2021.

CERQUEIRA, Daniel; BUENO, Samira (coords.). Atlas da violência 2020. Brasília: IPEA, 2020.

DELEUZE, Gilles. Conversações: 1972-1990. São Paulo: Editora 34, 1992.

ECO, Umberto. o fascismo eterno. Rio de Janeiro: Editora Record, 2018.

FANON, Frantz. Os condenados da terra. Rio de Janeiro: Editora Civilização Brasileira, 1968.

Pele negra, máscaras brancas. Salvador: EDUFBA, 2008. 
FOUCAULT, Michel. Vigiar e punir: nascimento da prisão. Petrópolis: Vozes, 1987.

História da sexualidade 3: O cuidado de si. 8. ed. Rio de Janeiro: Edições Graal, 1985.

Segurança, território e população: curso dado no Collège de France (1977-1978). São Paulo: Martins Fontes, 2008a.

. Nascimento da biopolítica: curso dado no Collège de France (1978-1979). São Paulo: Martins Fontes, 2008b.

GONÇALVES, Ricardo Juozepavicius. A superioridade racial em Immanuel Kant: as justificações da dominação europeia e suas implicações na América Latina. Kínesis, v. 7, n. 13, p. 179-195, jul. 2015. Disponível em: https://cutt.ly/hxbOPUM. Acesso em: 10 maio 2021.

HAN, Byung-Chul. La sociedad del cansacio. Barcelona: Herder, 2012.

INSTITUTO BRASILEIRO DE GEOGRAFIA E ESTATíSTICA (IBGE). Pesquisa Nacional por Amostra de Domicílios Contínua - PNAD Contínua. Rio de Janeiro: IBGE, 2021. Disponível em: https://cutt.ly/Qxb15r2. Acesso em: 10 maio 2021.

LIMA, Fátima. Bio-necropolítica: diálogos entre Michel Foucault e Achille Mbembe. Arquivo brasileiro de psicologia, v. 70, n. spe, p. 20-33, 2018. Disponível em: https://cutt.ly/cxb0lkh. Acesso em: 10 maio 2021.

LEVITSKY, Steven; ZIBLATT, Daniel. Como as democracias morrem. Rio de Janeiro: Zahar, 2018.

MBEMBE, Achille. On the postcolony. Berkeley: University of California Press, 2001.

Critique of black reason. Durham: Duke University Press, 2017.

. Necropolitics. Durham: Duke University Press, 2019.

NERI, Marcelo C. A escalada da desigualdade: qual foi o impacto da crise sobre a distribuição de renda e a pobreza? Rio de Janeiro: FGV, 2019. Disponível em: https://cutt.ly/pxbobgy. Acesso em: 10 maio 2021.

NIETZSCHE, Friedrich. Genealogia da moral. São Paulo: Companhia das Letras, 2009.

SANTANA, Bianca. Covid-19 e a população negra brasileira. Ecoa, Uol, SP, fev. 2021. Disponível em: https://cutt.ly/2xb0RRm. Acesso em: 10 maio 2021.

SOUZA, Jessé de. A elite do atraso: da escravidão a Bolsonaro. Rio de Janeiro: Estação Brasil, 2019.

VENTURA, Deisy; AITH, Fernando; REIS, Rossana. Propagação da Covid-19 no Brasil foi intencional. Folha de S.Paulo, SP, 2021. Disponível em: https://cutt.ly/6cyN3Jx. Acesso em: 10 maio 2021.

ZUBOFF, Shoshana. The age of surveillance capitalism: the fight for a human future at the new frontier of power. New York: Public Affairs, 2019. 